\title{
Effect of NiO spin orientation on the magnetic anisotropy of the Fe film in epitaxially grown $\mathrm{Fe} / \mathrm{NiO} / \mathrm{Ag}(001)$ and $\mathrm{Fe} / \mathrm{NiO} / \mathrm{MgO}(001)$
}

\author{
Wondong Kim, ${ }^{1,2}$ E. Jin, ${ }^{1}$ J. Wu, ${ }^{1}$ J. Park, ${ }^{1}$ E. Arenholz, ${ }^{3}$ A. Scholl, ${ }^{3}$ Chanyong Hwang, ${ }^{2}$ and \\ Z. Q. Qiu ${ }^{1}$
}

1Department of Physics, University of California Berkeley, Berkeley, CA 94720

2Division of Industrial Metrology, Korea Research Institute of Standards and

Science, 209 Gajeong-Ro, Yuseong-Gu, Daejeon 305-340, Korea

${ }^{3}$ Advanced Light Source, Lawrence Berkeley National Laboratory, Berkeley, CA 94720

\begin{abstract}
Single crystalline $\mathrm{Fe} / \mathrm{NiO}$ bilayers were epitaxially grown on $\mathrm{Ag}(001)$ and on $\mathrm{MgO}(001)$, and investigated by Low Energy Electron Diffraction (LEED), Magneto-Optic Kerr Effect (MOKE), and X-ray Magnetic Linear Dichroism (XMLD). We find that while the Fe film has an in-plane magnetization in both $\mathrm{Fe} / \mathrm{NiO} / \mathrm{Ag}(001)$ and $\mathrm{Fe} / \mathrm{NiO} / \mathrm{MgO}(001)$ systems, the $\mathrm{NiO}$ spin orientation changes from in-plane direction in $\mathrm{Fe} / \mathrm{NiO} / \mathrm{Ag}(001)$ to out-of-plane direction in $\mathrm{Fe} / \mathrm{NiO} / \mathrm{MgO}(001)$. These two different $\mathrm{NiO}$ spin orientations generate remarkable different effects that the $\mathrm{NiO}$ induced magnetic anisotropy in the Fe film is much greater in $\mathrm{Fe} / \mathrm{NiO} / \mathrm{Ag}(001)$ than in $\mathrm{Fe} / \mathrm{NiO} / \mathrm{MgO}(001)$. XMLD measurement shows that the much greater magnetic anisotropy in $\mathrm{Fe} / \mathrm{NiO} / \mathrm{Ag}(001)$ is due to a $90^{\circ}$-coupling between the in-plane $\mathrm{NiO}$ spins and the in-plane Fe spins.
\end{abstract}

PACS numbers: $75.70 . A k$ 


\section{Introduction}

Although an antiferromagnetic (AFM) material alone does not switch its spin direction within a magnetic field, the AFM layer could have a dramatic effect on a ferromagnetic (FM) layer in contact with it. For example, when cooling a FM/AFM bilayer system within a magnetic field from above to below the Neel temperature of the AFM layer, the FM layer hysteresis loop could shift in the applied magnetic field which is called exchange bias [1]. Even without field cooling, the AFM layer could induce a magnetic anisotropy in the FM layer to increase the FM layer coercivity [2]. These properties have been attributed to the unique character of FM/AFM interfacial interaction. Different from FM/FM interfacial interaction, the FM/AFM interfacial interaction is always accompanied by the so-called spin frustration that nearest neighbor coupling energy can not be minimized for all spin pairs at the same time. This characteristic property makes the FM/AFM bilayer system one of the most interesting and most intensively studied subject in nanomagnetism research.

Among many interesting phenomena related to the FM/AFM interfacial interaction, one fundamental issue is why and how the AFM layer induces a magnetic anisotropy in the FM layer. Phenomenally speaking, the AFM order breaks spatial rotational symmetry thus should in principle assign a magnetic anisotropy to the FM layer. Microscopically, however, it is not clear on how the FM/AFM interfacial interaction increases this magnetic anisotropy in the FM layer. Different mechanisms have been proposed to explain this phenomenon such as the spin flop coupling [3], local magnetic pinning centers [4], and the roughness-induced spin compensation [5], etc. In experiment, it is usually difficult to single out the exact effect of the AFM layer due to the difficulty of a direct measurement of the AFM spin structure and the difficulty of tuning the interfacial spin frustration. Regarding to the measurement, this difficulty is partially overcome by the recent development of X-ray Magnetic Linear Dichroism (XMLD) technique which could probe the spin direction in certain AFM thin films [6]. For example, it is now possible to directly measure the relative spin directions in some FM/AFM systems $[7,8]$ and use the result to explain the abnormal interlayer coupling between two FM layers across an AFM layer [9]. Regarding to the tuning of the interfacial spin frustration, recent effort is on the controlling of the magnetic spin direction rather than on the interfacial roughness so that geometric frustration can be partially separated from the intrinsic spin frustration. For example, it was recently shown that by switching the $\mathrm{Ni}$ spin direction from out-of-plane to in-plane directions in a $\mathrm{Ni} / \mathrm{FeMn}$ 
bilayer, the Neel temperature of the FeMn layer could be changed by $60 \mathrm{~K}$ without a change of the Ni/FeMn interfacial roughness [10]. This result demonstrates the importance of the FM spin orientation on the AFM properties. However, the reversed effect (e.g., the effect of the AFM spin orientation on the FM properties) has not yet been explored. We will address this issue in this work.

Among different FM/AFM bilayer systems, $\mathrm{Fe} / \mathrm{NiO}(001)$ has emerged as a model system because of the epitaxial growth between $\mathrm{Fe}$ and $\mathrm{NiO}$ and the big XMLD signal from the AFM NiO film. Although there exists certain degrees of intermixing and structural bulking [11], Fe/NiO can be synthesized into single crystalline ultrathin films which is crucial to the XMLD measurement. In this paper, we report our study on epitaxially grown $\mathrm{Fe} / \mathrm{NiO}$ bilayers. By growing a $20 \mathrm{~nm} \mathrm{Ag}(001)$ film on half of a $\mathrm{MgO}(001)$ substrate and the $\mathrm{Fe} / \mathrm{NiO}$ bilayer on both the $\mathrm{Ag}(001)$ and $\mathrm{MgO}(001)$ at the same time, we realized $\mathrm{Fe} / \mathrm{NiO} / \mathrm{Ag}(001)$ and $\mathrm{Fe} / \mathrm{NiO} / \mathrm{MgO}(001)$ under the same growth condition of the Fe/NiO bilayer. As shown by XMLD measurement, although the Fe film has an in-plane magnetization in both systems, the $\mathrm{NiO}$ spin has an in-plane direction in $\mathrm{Fe} / \mathrm{NiO} / \mathrm{Ag}(001)$ and an out-of-plane direction in $\mathrm{Fe} / \mathrm{NiO} / \mathrm{MgO}(001)$. Consequently, the different $\mathrm{NiO}$ spin orientations have dramatic different effects on the Fe film magnetic properties that the in-plane $\mathrm{NiO}$ spins induce a much greater magnetic anisotropy in the Fe layer than the out-of-plane $\mathrm{NiO}$ spins.

\section{Experiment}

A $10 \times 10 \mathrm{~mm}$ square shaped $\mathrm{MgO}(001)$ single crystal disk was used as the substrate. After ultrasonic cleaning, the substrate was introduced into an ultra high vacuum chamber of base pressure of $1-2 \times 10^{-10}$ Torr, and then annealed at $600^{\circ} \mathrm{C}$ for $\sim 10$ hours. After this treatment, the $\mathrm{MgO}(001)$ substrate exhibits a sharp $1 \mathrm{x} 1$ Low Energy Electron Diffraction (LEED) pattern [Figure 1(a)], showing that a well-defined single crystalline surface has been formed. A $20 \mathrm{~nm}$ Ag film was deposited on half of the $\mathrm{MgO}(001)$ substrate at room temperature using a thermal evaporator by blocking half of the $\mathrm{MgO}$ substrate with a knife-edged shutter in front of the substrate. In this way, we have both $\mathrm{Ag}(001)$ and $\mathrm{Mg}(001)$ surfaces from the same $10 \times 10 \mathrm{~mm}$ substrate. The film was annealed at $150^{\circ} \mathrm{C}$ after the $\mathrm{Ag}$ growth to improve the surface smoothness. LEED pattern from the $20 \mathrm{~nm} \mathrm{Ag}$ [Fig. 1(b)] shows that single crystalline $\mathrm{Ag}(001)$ surface has been formed.

A NiO film was grown onto this half-Ag and half-MgO substrate at room temperature by evaporating $\mathrm{Ni}$ at $\sim 1 \AA \AA$ min evaporation rate using a commercial electron-beam 
evaporator under $1 \times 10^{-6}$ Torr oxygen background pressure. The $\mathrm{NiO}$ film was grown into a wedge shape (0-30 ML) by moving the substrate behind the knife-edge shutter during the $\mathrm{NiO}$ growth. LEED measurement was taken again to check the structure of the $\mathrm{NiO}$ film [Fig. 1(c)-(d)]. As shown in the figure, the NiO film grown on both the Ag-covered part and the bare $\mathrm{MgO}(001)$ substrate shows well-ordered LEED spots, indicating an epitaxial growth of $\mathrm{NiO}$ on both $\mathrm{Ag}(001)$ and on $\mathrm{MgO}(001)$ substrates, in agreement with the literature result $[12,13]$. However, the LEED spots from $\mathrm{NiO} / \mathrm{Ag}(001)$ is broader than that of $\mathrm{NiO} / \mathrm{MgO}(001)$, showing that the $\mathrm{NiO}$ film surface is slightly rougher on $\mathrm{NiO} / \mathrm{Ag}$ than on $\mathrm{NiO} / \mathrm{MgO}$ although we couldn't provide a quantitative analysis. After pumping the vacuum chamber back to low 10-10 Torr, a uniform $8 \mathrm{ML}$ Fe film was grown on top of the $\mathrm{NiO}$ wedge and checked by LEED [Fig. 1(e)-(f)] to ensure the formation of single crystalline Fe film. The sample was then covered by a $10 \mathrm{ML}$ Ag to protect the film from contamination. Because both the $\mathrm{NiO}$ wedge and the Fe film were grown at the same time on both $\mathrm{Ag}$ and $\mathrm{MgO}$, our sample provides a direct comparison on samples of $\mathrm{Fe} / \mathrm{NiO} / \mathrm{Ag}(001)$ and $\mathrm{Fe} / \mathrm{NiO} / \mathrm{MgO}(001)$ so that effect due to growth condition variation can be eliminated in our experiment.

(a)

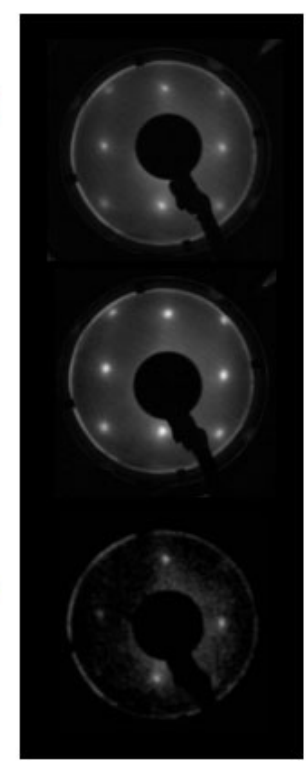

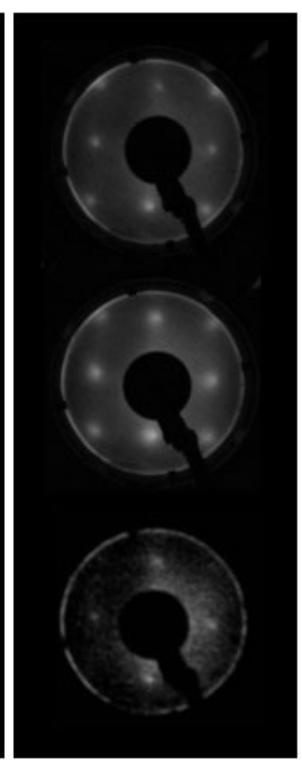

(b)

(d)

Figure 1: LEED patterns measured at $180 \mathrm{eV}$ electron energy from (a) clean $\mathrm{MgO}(001)$, (b) $\mathrm{Ag}(20 \mathrm{~nm}) / \mathrm{MgO}(001)$,

(c) $\quad \mathrm{NiO}(30 \mathrm{ML}) / \mathrm{MgO}(001)$, $\mathrm{NiO}(30 \mathrm{ML}) / \mathrm{Ag}(20 \mathrm{~nm}) / \mathrm{MgO}(001)$, (e) $\mathrm{Fe}(8 \mathrm{ML}) / \mathrm{NiO}(30 \mathrm{ML}) / \mathrm{MgO}(001)$ and (f) $\mathrm{Fe}(8 \mathrm{ML}) / \mathrm{NiO}(30 \mathrm{ML}) / \mathrm{Ag}(20 \mathrm{~nm}) / \mathrm{MgO}(001)$. 
Magneto Optical Kerr Effect (MOKE) measurement was performed to obtain the Fe hysteresis loop as a function of the $\mathrm{NiO}$ thickness for both $\mathrm{Fe} / \mathrm{NiO} / \mathrm{Ag}(001)$ and $\mathrm{Fe} / \mathrm{NiO} / \mathrm{MgO}(001)$ along the $\mathrm{NiO}$ wedge. A He-Ne laser was used as the light source and a rotatable magnet applies a magnetic field to the film in both the in-plane and outof-plane directions. X-ray Absorption Spectroscopy (XAS) and X-ray Magnetic Linear Dichroism (XMLD) measurements were performed at beamline 4.0.2 of the Advanced Light Source of Lawrence Berkeley National Laboratory. The incident x-ray has a $99 \pm 1 \%$ linear polarization. The linear polarization vector of the x-ray can be controlled by adjusting the gap of the elliptically polarized undulator at the beamline. XAS was obtained in total electron yield mode by measuring the sample current. The x-ray beam size is about $100 \times 100 \mu \mathrm{m}$, which is estimated to cover only $\sim 0.4 \mathrm{ML}$ thickness range of the $\mathrm{NiO}$ wedge so that measurement at a given location of the $\mathrm{NiO}$ wedge can be regarded as a measurement from a uniformly thick $\mathrm{NiO}$ film.

\section{Result and Discussion}

The Fe hysteresis loops were measured at room temperature. No polar loops were detected showing that the $8 \mathrm{ML}$ Fe film has an in-plane magnetization in both $\mathrm{Fe} / \mathrm{NiO} / \mathrm{Ag}(001)$ and $\mathrm{Fe} / \mathrm{NiO} / \mathrm{MgO}(001)$ systems. Therefore we show only the $\mathrm{Fe}$ inplane hysteresis loops in this paper. Fig. 2 shows the Fe in-plane hysteresis loops at different $\mathrm{NiO}$ thicknesses in both $\mathrm{Fe} / \mathrm{NiO} / \mathrm{Ag}(001)$ and $\mathrm{Fe} / \mathrm{NiO} / \mathrm{MgO}(001)$. The external magnetic field was applied in the $\mathrm{NiO}$ [110] axis direction, which is the $\mathrm{Fe}$ [100] easy magnetization axis of bcc Fe. Below 7ML NiO thickness, both $\mathrm{Fe} / \mathrm{NiO} / \mathrm{Ag}(001)$ and $\mathrm{Fe} / \mathrm{NiO} / \mathrm{MgO}(001)$ show a small coercivity $(<50 \mathrm{Oe})$. The small different coercivities of these two systems are attributed to either the different surface roughness of the $\mathrm{NiO}$ film as revealed by the LEED patterns in Fig. 1 or to the slight different $\mathrm{NiO}$ strains due to the different $\mathrm{Ag}$ and $\mathrm{MgO}$ lattice constants. As the $\mathrm{NiO}$ film thickness increases above $7 \mathrm{ML}$, the coercivity of the $\mathrm{Fe} / \mathrm{NiO} / \mathrm{Mg}(001)$ film increases only slightly to $\sim 75$ Oe but the coercivity of the $\mathrm{Fe} / \mathrm{NiO} / \mathrm{Ag}(001)$ film increases drastically to as high as $375 \mathrm{Oe}$. We attribute this coercivity enhancement to the AFM order of the NiO layer above $7 \mathrm{ML}$ at room temperature. The coercivity enhancement of a ferromagnetic layer in contact with an AFM layer is a common phenomenon in FM/AFM systems. The AFM order should in principle induce an exchange bias and a magnetic anisotropy [2] to the FM layer. Since the Fe film in our sample was grown on top of the NiO layer and no field cooling was performed, we expect only an enhancement of the magnetic coercivity in our sample. We noticed that $\mathrm{H}_{\mathrm{C}}$ has a peak at $\sim 10 \mathrm{ML} \mathrm{NiO}$ and followed by a slow decrease with $\mathrm{NiO}$ 
thickness in $\mathrm{Fe} / \mathrm{NiO} / \mathrm{MgO}(001)$. This result shows that there also exists $\mathrm{Fe} / \mathrm{NiO}$ magnetic coupling. The peak behavior was reported in the literature [2] and has to come from the change of the $\mathrm{Fe} / \mathrm{NiO}$ interfacial interaction. But it is unclear at this moment on whether it is due to the thickness dependent $\mathrm{NiO}$ magnetic anisotropy or the thickness dependent $\mathrm{NiO}$ spin orientation. Future studies are needed to resolve this issue.
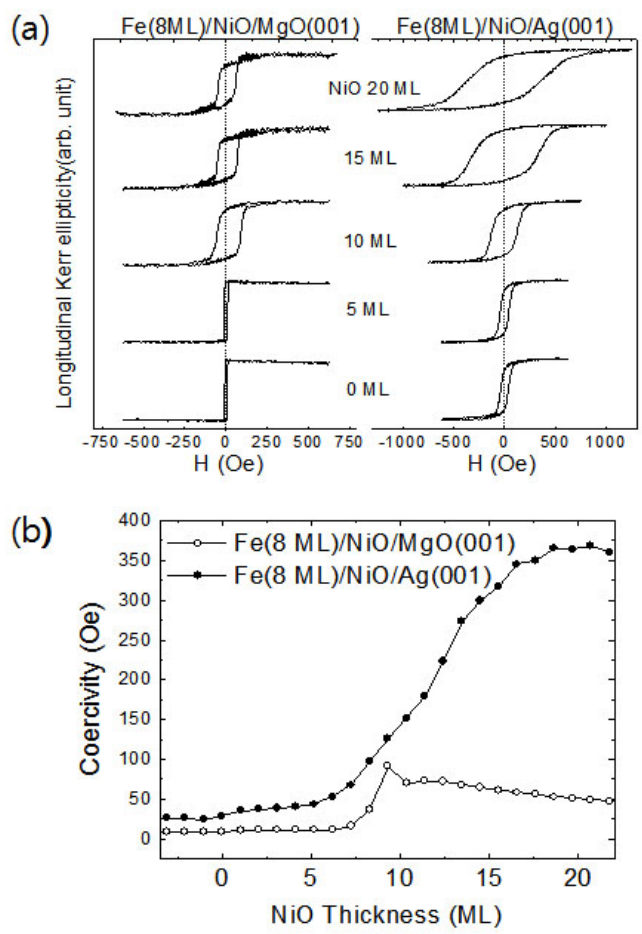

Figure 2: (a) Hysteresis loops and (b) coercivity of $\mathrm{Fe}(8 \mathrm{ML}) / \mathrm{NiO} / \mathrm{Ag}(001)$ and $\mathrm{Fe}(8 \mathrm{ML}) / \mathrm{NiO} / \mathrm{MgO}(001)$ at room temperature as a function of $\mathrm{NiO}$ thickness. The AFM order of the $\mathrm{NiO}$ film above $7 \mathrm{ML} \mathrm{NiO}$ results in a much greater $\mathrm{Fe}$ coercivity enhancement in $\mathrm{Fe} / \mathrm{NiO} / \mathrm{Ag}(001)$ than in $\mathrm{Fe} / \mathrm{NiO} / \mathrm{MgO}(001)$.

The next question is why the coercivity enhancement occurs only above $7 \mathrm{ML} \mathrm{NiO}$. This is because the magnetic ordering temperature of a magnetic thin film depends on its film thickness due to the dimensionality effect. In fact, a reduction of the Curie temperature in FM thin films has been known for a long time [14]. Recent experiment on AFM films suggests that the Neel temperature of an AFM thin film is also reduced in ultrathin regime [15]. Therefore, the coercivity enhancement of the Fe film above 7ML $\mathrm{NiO}$ in our samples simply reflects the fact that the $\mathrm{NiO}$ film at room temperature is at 
AFM state above $7 \mathrm{ML}$ but paramagnetic state below 7ML. To confirm this statement, we grow a new sample of $\mathrm{Fe}(8 \mathrm{ML}) / \mathrm{Ag}(3 \mathrm{ML}) / \mathrm{NiO}(12 \mathrm{ML}) / \mathrm{Ag}(001)$ and performed temperature dependent measurement. The $3 \mathrm{ML} \mathrm{Ag}$ is used to prevent intermixing between $\mathrm{Fe}$ and $\mathrm{NiO}$ at high temperature but to retain the $\mathrm{Fe} / \mathrm{NiO}$ magnetic interaction. Fe hysteresis loops were taken at different temperatures. As shown Fig. 3, the coercivity of the sample decreases with increasing the temperature above the Neel temperature and is fully recovered after cooling down the sample to room temperature. This result proves that the coercivity enhancement shown in Fig. 2 above $7 \mathrm{ML} \mathrm{NiO}$ is indeed due to the AFM order of the NiO layer.

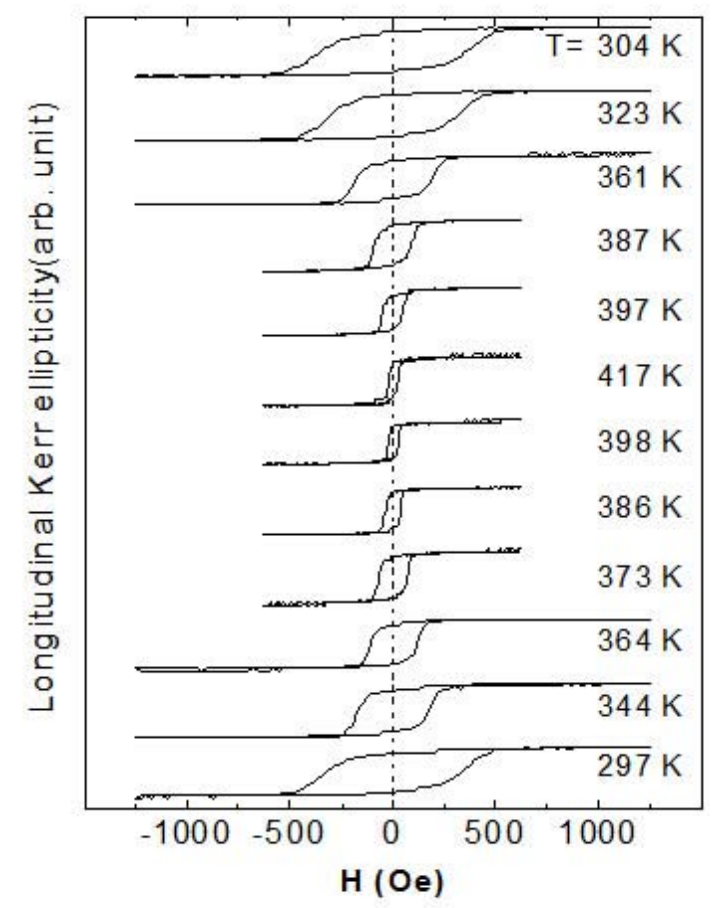

Figure 3: Temperature dependence of the $\mathrm{Fe}$ hysteresis loops of $\mathrm{Fe}(8 \mathrm{ML}) / \mathrm{Ag}(3 \mathrm{ML}) / \mathrm{NiO}(12 \mathrm{ML}) / \mathrm{Ag}(001)$. The result proves that the $\mathrm{Fe}$ coercivity enhancement is due to the $\mathrm{NiO}$ antiferromagnetic order $\left(\mathrm{T}_{\mathrm{N}}=400 \mathrm{~K}\right.$ for $12 \mathrm{ML} \mathrm{NiO}$ ).

The most remarkable result of Fig. 2 is that the coercivity enhancement of the Fe film in $\mathrm{Fe} / \mathrm{NiO} / \mathrm{Ag}(001)$ is much greater than that in $\mathrm{Fe} / \mathrm{NiO} / \mathrm{MgO}(001)$. This result can not be explained by the different film roughness or different $\mathrm{Ag}$ and $\mathrm{MgO}$ lattice constants because the coercivity difference between $\mathrm{Fe} / \mathrm{NiO} / \mathrm{Ag}$ and $\mathrm{Fe} / \mathrm{NiO} / \mathrm{MgO}$ below $7 \mathrm{ML} \mathrm{NiO}$ is much smaller than the difference above $7 \mathrm{ML} \mathrm{NiO}$. Then the much greater 
coercivity enhancement in $\mathrm{Fe} / \mathrm{NiO} / \mathrm{Ag}(001)$ than in $\mathrm{Fe} / \mathrm{NiO} / \mathrm{MgO}(001)$ must come from the different $\mathrm{Fe} / \mathrm{NiO}$ magnetic interactions in these two systems, i.e., the AFM order of the $\mathrm{NiO}$ film in $\mathrm{NiO} / \mathrm{Ag}(001)$ and $\mathrm{NiO} / \mathrm{MgO}(001)$ must have induced different magnetic anisotropies in the Fe film. In our sample, both $\mathrm{Fe} / \mathrm{NiO} / \mathrm{Ag}(001)$ and $\mathrm{Fe} / \mathrm{NiO} / \mathrm{MgO}(001)$ have the same 8ML Fe FM layer and MOKE measurement shows the same magnitude of their hysteresis loops, thus the coercivity difference can not come from the different Fe magnetic moment in these two system. Regarding to the $\mathrm{NiO}$ layer, although the $\mathrm{NiO}$ magnetic property could in principle depend on the $\mathrm{NiO}$ growth condition (e.g., oxygen deficiency), the fact that the $\mathrm{NiO}$ wedge in our $\mathrm{Fe} / \mathrm{NiO} / \mathrm{Ag}(001)$ and $\mathrm{Fe} / \mathrm{NiO} / \mathrm{Mg}(001)$ was grown at the same time can safely rule out the different $\mathrm{NiO}$ growth conditions in these two samples. After ensuring the same $\mathrm{Fe}$ and $\mathrm{NiO}$ films in our $\mathrm{Fe} / \mathrm{NiO} / \mathrm{Ag}(001)$ and $\mathrm{Fe} / \mathrm{NiO} / \mathrm{MgO}(001)$, the only possibility for the different coercivity enhancement in these two systems is that the NiO film has different AFM spin structures in these two systems. In the following, we discuss the different $\mathrm{NiO}$ spin orientations in $\mathrm{Fe} / \mathrm{NiO} / \mathrm{Ag}(001)$ and $\mathrm{Fe} / \mathrm{NiO} / \mathrm{MgO}(001)$ systems.

Bulk $\mathrm{NiO}$ has the rock-salt crystal structure with its AFM order accompanied by a small rhombohedral distortion along a [111] direction. The $\mathrm{Ni}^{2+}$ spins are ferromagnetically aligned within each (111) plane and antiferromagnetically aligned between adjacent (111) planes with a total of 24 energetically degenerate domain orientations in a bulk $\mathrm{NiO}$ single crystal [16]. In thin films, however, the $\mathrm{NiO}$ spins are usually modified due to strains imposed by the substrate. In particular, NiO film grown on $\mathrm{MgO}(001)$ and $\mathrm{Ag}(001)$ exhibits an out-of-plane [13] and in-plane [17] spin directions, respectively. In fact, it was demonstrated that the $\mathrm{NiO}$ spin direction could even be manipulated between out-of-plane and in-plane directions in a $\mathrm{MgO} / \mathrm{NiO} / \mathrm{Ag}(001)$ sandwich [12], or within the film plane by a vicinal $A g(001)$ surface [15]. Then the interesting question is what's the $\mathrm{NiO}$ spin direction after covering the $\mathrm{NiO} / \mathrm{Ag}(001)$ and $\mathrm{NiO} / \mathrm{MgO}(001)$ with a $8 \mathrm{ML}$ Fe overlayer? This would be a trivial question if the $\mathrm{Fe} / \mathrm{NiO}$ interfacial interaction has a collinear coupling. In that case, the in-plane $\mathrm{Fe}$ magnetization would obviously result in an in-plane $\mathrm{NiO}$ spin direction. However, it is well known that FM/AFM interfacial interaction could result in a $90^{\circ}$-coupling between the FM and AFM spins. Therefore even though it might be trivial for the $\mathrm{NiO}$ spins to remain in-plane direction in the $\mathrm{Fe} / \mathrm{NiO} / \mathrm{Ag}(001)$ system, it is unclear that if the $\mathrm{NiO}$ spin direction should remain in the out-of-plane direction in the $\mathrm{Fe} / \mathrm{NiO} / \mathrm{MgO}(001)$ system. To answer this question, we carried out XMLD measurement on $\mathrm{Fe} / \mathrm{NiO} / \mathrm{Ag}(001)$ and $\mathrm{Fe} / \mathrm{NiO} / \mathrm{MgO}(001)$. 
Fig. 4 depicts the XMLD measurement result on the $\mathrm{Ni} L_{2}$ edge of $\mathrm{Fe} / \mathrm{NiO}(30$ $\mathrm{ML}) / \mathrm{MgO}(001)$. The polarization of the linearly polarized $\mathrm{x}$-ray lies in the incident plane so that as the incident angle varies the XAS could pick up the out-of-plane component of the $\mathrm{NiO}$ spins. This is actually the measurement geometry in the literature to prove that $\mathrm{NiO} / \mathrm{MgO}(001)$ has an out-of-plane spin direction [13]. As shown in Fig. 4, the XAS shows a typical double peak feature at the $\mathrm{Ni} L_{2}$ absorption edge. The $L_{2}$ ratio $R_{L 2}$ (defined as the lower energy peak intensity divided by the higher energy peak intensity) exhibits a strong polarization dependence at different incident angles with the well-known $\cos ^{2} \theta$-dependence reported for the $\mathrm{NiO} / \mathrm{MgO}(001)$ system [13], showing that the $\mathrm{NiO}$ spin in the $\mathrm{Fe} / \mathrm{NiO} / \mathrm{MgO}(001)$ also has an out-of plane spin component.
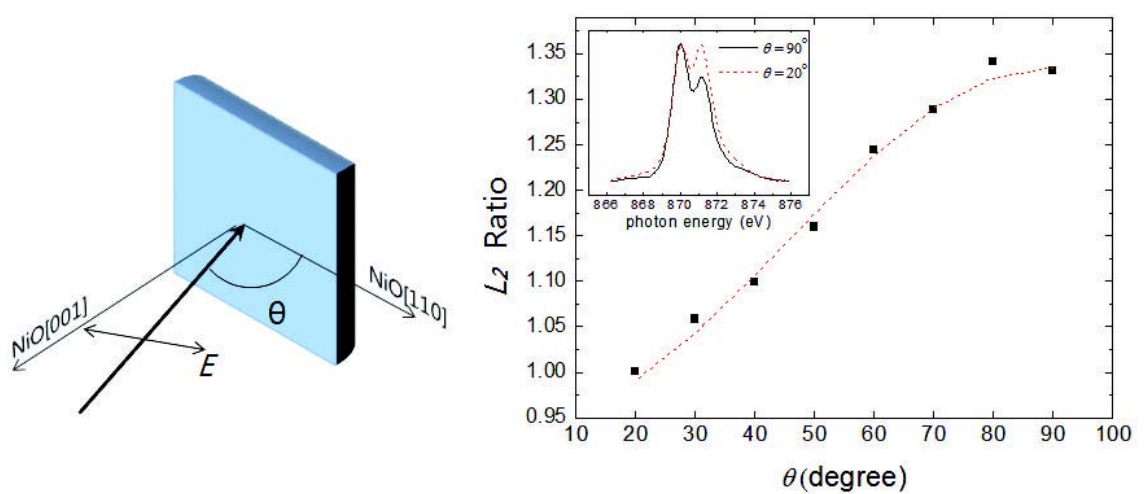

Figure 4: (Color online) $\mathrm{Ni}_{2}$ edge $x$-ray absorption spectra (inset) and the $\theta$ dependence of the $\mathrm{L}_{2}$ ratio of $\mathrm{Fe}(8 \mathrm{ML}) / \mathrm{NiO}(30 \mathrm{ML}) / \mathrm{MgO}(001)$. The $\cos ^{2} \theta-$ dependence (dotted line) shows that the $\mathrm{NiO}$ spins have an out-of-plane component in the $\mathrm{Fe}(8 \mathrm{ML}) / \mathrm{NiO}(30 \mathrm{ML}) / \mathrm{MgO}(001)$.

To clarify the in-plane spin direction of the $\mathrm{NiO}$ film in the $\mathrm{Fe} / \mathrm{NiO} / \mathrm{MgO}(001)$, we performed the XMLD measurement at normal incidence but at different polarization angle $(\phi)$ of the linearly polarized x-ray (Fig. 5). In this way, a $\phi$-dependent $L_{2}$ ratio would reflect the in-plane $\mathrm{NiO}$ spin component. The result shows that the $\mathrm{Fe} / \mathrm{NiO} / \mathrm{MgO}(001)$ has an negligible in-plane $\mathrm{NiO}$ spin component. In combination with the result of Fig. 4, we conclude that the $\mathrm{NiO}$ in $\mathrm{Fe} / \mathrm{NiO} / \mathrm{MgO}(001)$ film has an out-ofplane spin direction. In contrast, the $L_{2}$ ratio of $\mathrm{Fe} / \mathrm{NiO} / \mathrm{Ag}(001)$ at normal incidence of the x-ray shows a clear $\cos ^{2} \phi$ dependence (Fig. 5). After switching the $\mathrm{Fe}$ magnetization by an external magnetic field from the $\mathrm{NiO}$ [110] to [1 10 ] directions, the $\mathrm{Ni}$ $L_{2}$ ratio is revised accordingly (Fig. 5). This result shows that the $\mathrm{NiO}$ spins in $\mathrm{Fe} / \mathrm{NiO} / \mathrm{Ag}(001)$ have an in-plane direction as in the $\mathrm{NiO} / \mathrm{Ag}(001)$ system. We also 
carried out the XMLD measurement for thinner NiO films and observe the same results down to $\sim 10 \mathrm{ML} \mathrm{NiO}$ below which the XMLD signal is too weak to determine the spin direction. We then determined the in-plane $\mathrm{NiO}$ spin direction relative to the $\mathrm{Fe}$ magnetization direction. Fig. 5 shows a $\cos ^{2} \phi$ dependence of the $L_{2}$ ratio with the minimum/maximum values occurring at $\phi=0^{\circ}$ ( $\mathrm{NiO}[110]$ axis) and $\phi=90^{\circ}$ ( $\mathrm{NiO}[1 \overline{1} 0]$ axis). This result shows that the $\mathrm{NiO}$ spin direction is along the $\mathrm{NiO}$ [110] or [1 10 ] axis. For $\mathrm{NiO}$ spin direction in the [110] axis, the $L_{2}$ ratio should reach maximum value as the $x$-ray polarization direction is parallel to the $\mathrm{NiO}$ spin axis, opposite to the [100] $\mathrm{NiO}$ easy axis case where the $L_{2}$ ratio reaches its minimum value as the $x$-ray polarization direction is parallel to the $\mathrm{NiO}$ spin axis $[18,19]$. Then the result of Fig. 5 shows that the in-plane $\mathrm{NiO}$ spins have a $90^{\circ}$-coupling to the $\mathrm{Fe}$ spins in the $\mathrm{Fe} / \mathrm{NiO} / \mathrm{Ag}(001)$ sample. In addition, the $\mathrm{NiO}$ spins rotate by $90^{\circ}$ after the Fe magnetization is switched by $90^{\circ}$, i.e., the $\mathrm{NiO}$ spins are locked to the Fe spins to rotate together with the Fe spins.
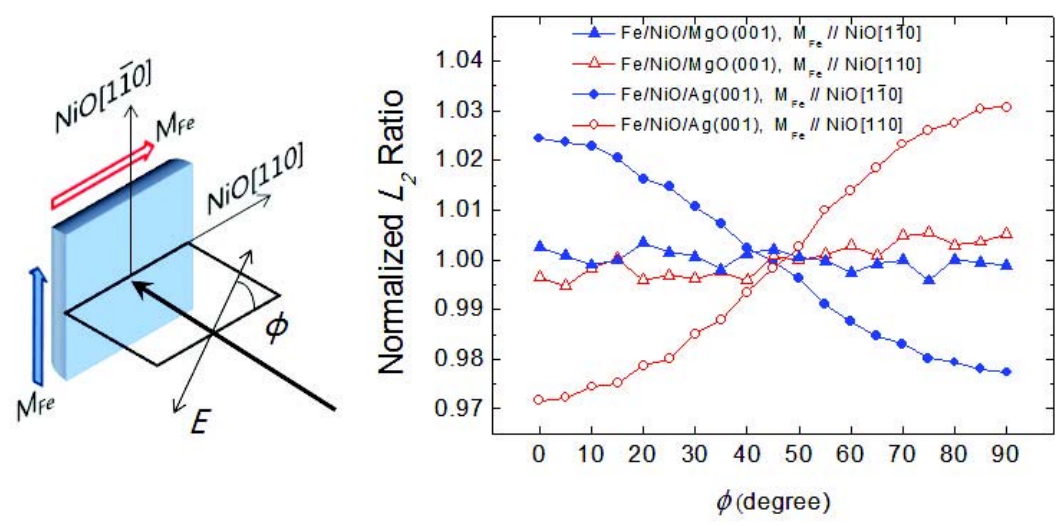

Figure 5: (Color online) $\mathrm{Ni} L_{2}$ ratio at normal incidence of the $\mathrm{x}$-rays from $\mathrm{Fe}(8 \mathrm{ML}) / \mathrm{NiO}(30 \mathrm{ML}) / \mathrm{Ag}(001)$ and $\mathrm{Fe}(8 \mathrm{ML}) / \mathrm{NiO}(30 \mathrm{ML}) / \mathrm{MgO}(001)$. The $\mathrm{Fe}$ magnetization is aligned by an external field to the $\mathrm{NiO}\left[1 \overline{\mathbf{I}}_{0}\right.$ ] (filled symbols) and $\mathrm{NiO}$ [110] directions (hollow symbols), respectively during the measurement. The result shows that the $\mathrm{NiO}$ spins in $\mathrm{Fe}(8 \mathrm{ML}) / \mathrm{NiO}(30 \mathrm{ML}) / \mathrm{Ag}(001)$ is in the film plane and $90^{\circ}$ coupled to the $\mathrm{Fe}$ magnetization, and that the $\mathrm{NiO}$ spins in $\mathrm{Fe}(8 \mathrm{ML}) / \mathrm{NiO}(30 \mathrm{ML}) / \mathrm{MgO}(001)$ is in the out-of-plane direction.

The XMLD measurement clearly shows that the NiO layer has different spin orientations in $\mathrm{Fe} / \mathrm{NiO} / \mathrm{Ag}(001)$ and $\mathrm{Fe} / \mathrm{NiO} / \mathrm{MgO}(001)$ systems. This result explains the hysteresis loop result that the $\mathrm{Fe}$ coercivity in $\mathrm{Fe} / \mathrm{NiO} / \mathrm{Ag}(001)$ is much greater than that 
in $\mathrm{Fe} / \mathrm{NiO} / \mathrm{MgO}(001)$. For the case of $\mathrm{Fe} / \mathrm{NiO} / \mathrm{MgO}(001)$, the $\mathrm{NiO}$ spins are in the out-ofplane direction so that as the Fe spins are rotated in the film plane by an external magnetic field, the $\mathrm{NiO}$ spins are not changing their directions thus will not add additional magnetic anisotropy to the $\mathrm{Fe}$ film. That is why the $\mathrm{Fe}$ coercivity in the $\mathrm{Fe} / \mathrm{NiO} / \mathrm{MgO}(001)$ changes so little as the $\mathrm{NiO}$ establishes AFM order above $7 \mathrm{ML}$ thickness. However, the $90^{\circ}$-coupling between $\mathrm{Fe}$ and $\mathrm{NiO}$ should tilt the $\mathrm{Fe}$ and $\mathrm{NiO}$ spins a tiny bit to produce a small parallel component of the $\mathrm{NiO}$ spins in the Fe spin direction. Although this tiny parallel component is beyond the XMLD measurement limit, we believe it accounts for the small increase of the Fe coercivity in the $\mathrm{Fe} / \mathrm{NiO} / \mathrm{MgO}(001)$ above $7 \mathrm{ML} \mathrm{NiO}$ thickness. For the case of the $\mathrm{Fe} / \mathrm{NiO} / \mathrm{Ag}(001)$, the XMLD result shows that the $\mathrm{NiO}$ spins are in the film plane and are $90^{\circ}$ coupled to the Fe spins. Therefore, as the Fe spins are rotated by an external magnetic field, the $\mathrm{Fe} / \mathrm{NiO}$ coupling also drags the $\mathrm{NiO}$ spins to rotate together with the Fe magnetization so that the Fe spins should carry the effect of the $\mathrm{NiO}$ magnetic anisotropy during its magnetization reversal, leading to a much greater Fe coercivity than that generated by the Fe magnetic anisotropy alone. This explains the $\mathrm{Fe} / \mathrm{NiO} / \mathrm{Ag}(001)$ result that the Fe coercivity is greatly enhanced after the $\mathrm{NiO}$ film establishes AFM order above $7 \mathrm{ML}$ thickness. It should be mentioned that the $\mathrm{NiO}$ spins in the $\mathrm{Fe} / \mathrm{NiO} / \mathrm{MgO}(001)$ should be titled away from the surface normal direction due to the $\mathrm{Fe} / \mathrm{NiO}$ interfacial interaction. To make a rough estimation of the $\mathrm{NiO}$ tilting angle, we make an over simplified assumption that the coercivity enhancement is entirely determined by the in-plane $\mathrm{NiO}$ component for both $\mathrm{Fe} / \mathrm{NiO} / \mathrm{MgO}(001)$ and $\mathrm{Fe} / \mathrm{NiO} / \mathrm{Ag}(001)$. Under this assumption, the ratio of the coercivity enhancement for these two cases would give the tilting angle $\tan \alpha \sim \Delta \mathrm{Hc}(\mathrm{Fe} / \mathrm{NiO} / \mathrm{MgO}) / \Delta \mathrm{Hc}(\mathrm{Fe} / \mathrm{NiO} / \mathrm{Ag}) \sim 50 / 350=0.14$ or $\alpha \sim 8^{\circ}$. This is only a rough estimation because other factors such as roughness and strain are not considered.

\section{Summary.}

We investigated $\mathrm{Fe} / \mathrm{NiO} / \mathrm{Ag}(001)$ and $\mathrm{Fe} / \mathrm{NiO} / \mathrm{MgO}(001)$ using MOKE and XMLD techniques. Although the Fe film in both systems has an in-plane magnetization, XMLD measurement shows that the $\mathrm{NiO}$ spins are in the film plane in the $\mathrm{Fe} / \mathrm{NiO} / \mathrm{Ag}(001)$ and out-of-plane in the $\mathrm{Fe} / \mathrm{NiO} / \mathrm{MgO}(001)$. In addition, the in-plane $\mathrm{NiO}$ spins in the $\mathrm{Fe} / \mathrm{NiO} / \mathrm{Ag}(001)$ are $90^{\circ}$ coupled to the $\mathrm{Fe}$ magnetization to rotate together with the $\mathrm{Fe}$ magnetization. This result explains the Fe hysteresis loop measurement that as the $\mathrm{NiO}$ thickness increases to establish its antiferromagnetic order, the $\mathrm{Fe}$ coercivity is greatly enhanced in $\mathrm{Fe} / \mathrm{NiO} / \mathrm{Ag}(001)$ while only slightly enhanced in $\mathrm{Fe} / \mathrm{NiO} / \mathrm{MgO}(001)$. 
Therefore we conclude that the in-plane $\mathrm{NiO}$ spins have a much stronger effect on the inplane Fe magnetic anisotropy than the out-of-plane $\mathrm{NiO}$ spins.

\section{Acknowledgement}

This work was supported by National Science Foundation DMR-0803305, U.S. Department of Energy DE-AC02-05CH11231, and KICOS through Global Research Laboratory project. 


\section{References:}

1. W. H. Meiklejohn and C. P. Bean, Phys. Rev. 102, 1413 (1956).

2. J. Nogués and Ivan K. Schuller, J. of Magn. Mag. Mat. 192, 203 (1999).

3. N. C. Koon, Phys. Rev. Lett. 78, 4865 (1997).

4. W. Kuch, F. Offi, L. I. Chelaru, M. Kotsugi, K. Fukumoto, and J. Kirschner, Phys. Rev. B 65, 140408 (2002).

5. J. Wu, J. Choi, A. Scholl, A. Doran, E. Arenholz, Chanyong Hwang, and Z. Q. Qiu, Phys. Rev. B 79, 212411 (2009).

6. A. Scholl, J. Stöhr, J. Lüning, J. W. Seo, J. Fompeyrine, H. Siegwart, J.-P. Locquet, F. Nolting, S. Anders, E. E. Fullerton, M. R. Scheinfein, H. A. Padmore, Science 287, 1014 (2000).

7. H. Ohldag, T. J. Regan, J. Stöhr, A. Scholl, F. Nolting, J. Lüning, C. Stamm, S. Anders, and R. L. White, Phys. Rev. Lett. 87, 247201 (2001).

8. M. Finazzi, A. Brambilla, P. Biagioni, J. Graf, G.-H. Gweon, A. Scholl, A Lanzara, and L. Duò, Phys. Rev. Lett. 97, 097202 (2006).

9. J. Wu, J. Choi, A. Scholl, A. Doran, E. Arenholz, Y. Z. Wu, C. Won, Chanyong Hwang, and Z. Q. Qiu, Phys. Rev. B 80, 012409 (2009).

10. K. Lenz, S. Zander, and W. Kuch, Phys. Rev. Lett. 98, 237201 (2007).

11. P. Luches, V. Bellini, S. Colonna, L. Di Giustino, F. Manghi, S. Valeri, and F. Boscherini, Phys. Rev. Lett. 96, 106106 (2006).

12. S. Altieri, M. Finazzi, H. H. Hsieh, H. -J. Lin, C.T. Chen, T. Hibma, S. Valeri, and G. A. Sawatzky, Phys. Rev. Lett. 91, 137201 (2003).

13. D. Alders, L. H. Tjeng, F. C. Voogt, T. Hibma, G. A. Sawatzky, C. T. Chen, J. Vogel, M. Sacchi, and S. lacobucci, Phys. Rev. B 57, 11623 (1998).

14. Renjun Zhang and Roy F. Willis, Phys. Rev. Lett. 86, 2665 (2001).

15. Y. Z. Wu, Y. Zhao, E. Arenholz, A. T. Young, B. Sinkovic, C. Won, and Z. Q. Qiu, Phys. Rev. B 78, 064413 (2008).

16. F. Keffer and W. O'Sullivan, Phys. Rev. 108, 637 (1957). 
17. D. Spanke, V. Solinus, D. Knabben, F. U. Hillebrecht, F. Ciccacci, L. Gregoratti, and M. Marsi, Phys. Rev. B 58, 5201 (1998).

18. Elke Arenholz, Gerrit van der Laan,, Rajesh V. Chopdekar, and Yuri Suzuki, Phys. Rev. Lett. 98, 197201 (2007).

19. I. P. Krug, F. U. Hillebrecht, M. W. Haverkort, A. Tanaka, L. H. Tjeng, H. Gomonay, A. FraileRodríguez, F. Nolting, S. Cramm, and C. M. Schneider, Phys. Rev. B 78, 064427 (2008). 